\title{
National Doctor's Day - conserving one of South Africa's greatest assets
}

Doctors are among South Africa (SA)'s greatest home-grown assets. They respond creatively and courageously to a daily storm of healthcare challenges, which ironically makes them sought after globally, and even more importantly, crucial to retain domestically.

A long-overdue National Doctor's Day, honouring our doctors' commitment, innovation and internationally recognised achievements, is being circled in SA diaries for 16 November.

The initiative is aimed at affirming, celebrating and highlighting the contribution doctors make to SA society and the world - and keeping them in this country as a critical, endangered resource. Their local challenges are legion, ranging from the fast-changing healthcare regulatory framework and a growing climate of litigation to a stark burden of disease aggravated by endemic violence and trauma. In the state sector, administrative dysfunction, shortages of equipment and facilities and lack of adequate supervision for junior doctors are standard, accompanied by thankfully isolated instances of political and union victimisation. There are far too few doctors to cater for the growing population, in spite of valiant state measures to increase our training output. To illustrate, an Econex study for the Hospital Association of SA found that there are 25 state doctors per 100000 people in the public sector and 92 doctors per 100000 in the private sector, which translates to $16 \%$ and $60 \%$ of the world average ratio (152 doctors per 100000 population). Even in India (70), Brazil (189) and China (194) there are more doctors per 100000 people. ${ }^{[1]}$ SA's ratio is unlikely to improve for at least a decade or two. Task shifting and referring similar healthcare cases to dedicated facilities are among parallel antidotes being prescribed. Without sufficient public recognition for their stellar work in unforgiving circumstances, we stand to lose more and more doctors to overseas countries hungry for their skills and seldom-rivalled experience. Perhaps worse, our patients, who lie at the heart of all these efforts, will suffer. Whether they be interns working long hours, community service officers doing their compulsory 1-year service, GPs or even the most thinly spread specialists, our doctors continue to excel by rising above the challenges, often at great personal expense to their families, loved ones and leisure time.

\section{Star-studded researchers, clinicians and teachers lead the way}

The hard-pressed public healthcare sector has produced scores of academics whose laboratory research has saved thousands of lives and translated to hands-on patient care, taking them to the top of their fields globally. Disciplines in which South Africans excel range from infectious diseases to highly specialised fields such as neurosurgery. Prof. Glenda Gray, president and CEO of the South African Medical Research Council, was last year listed by Time magazine as one of the world's 100 most influential people for her work towards producing an effective HIV vaccine. The University of Cape Town's Prof. LindaGail Bekker, Deputy Director of the Desmond Tutu HIV Centre at the Institute of Infectious Disease and Molecular Medicine, is currently president of the International AIDS Society, while Prof. Helen Rees, OBE, of the University of the Witwatersrand, is globally renowned as an expert in HIV prevention, reproductive health and vaccines. Her Wits colleague Prof. Lynn Morris is also internationally recognised for her work in understanding how the antibody response to HIV develops, and won the 2018 World Academy of Sciences Prize in the Medical Sciences category. In a single unit at UCT, the Department of Neurosurgery, three of the professors are world leaders Prof. Anthony Figaji is president of the International Neurotrauma Society, Prof. Graham Fieggen is president of the International Society of Paediatric Neurosurgeons, and Prof. Allan Taylor is incoming president of the World Federation of Interventional and Therapeutic Neuroradiology. Wits surgery department chief and seasoned trauma specialist Prof. Ken Boffard in 2015 led a Netcare Milpark Hospital surgical team that extracted a $2 \mathrm{~m}$ long, $2 \mathrm{~cm}$ thick industrial crowbar that had impaled a mining engineer from groin to upper back. The miner walked out of the hospital healthy with one kidney missing after 19 days. Unsurprisingly, Boffard is the immediate past president of the International Trauma Society. Wits Prof. Shabir Madhi helped develop the rotavirus, pentavalent and pneumococcal conjugate vaccines, which today form part of the government's national Expanded Programme of Immunisation, potentially saving thousands of lives. Globally renowned cardiologist and the former dean of health sciences at UCT, Prof. Bongani Mayosi, who died tragically earlier this year, epitomised selfless service in difficult circumstances. When other black leaders were benefiting from BEE shares in companies, he was asking for funding of $\mathrm{PhD}$ grants for students and mentoring scores of young doctors. Bestowed SA's highest honour, the Order of Mapungubwe, in 2009, he remains a beacon of Mandela-like proportions in medicine and has proved a rallying point for those fighting to prevent all-too-frequent academic and clinical burnout. These are a few examples of a stellar cast that spreads far wider across many more health science faculties.

\section{Rural doctors up the bar}

In our isolated rural districts where junior doctors learn skills and tailor-make creative solutions that prove the envy of their colleagues when they practise overseas, those who mentor them are often seasoned community change agents - like 62-year-old Dr Victor Fredlund, CEO at Mseleni Hospital in the Maputaland region of KwaZulu-Natal. Winner of the 2016 Rural Doctors Association of South Africa's Lifetime Achiever Award, his leadership and compassion have impacted on every sphere of life in his district. Among a handful of physicians to first describe the globally rare, locally occurring Mseleni hip disease, Fredlund's impact over his 40-year tenure has been prodigious. From building toilets to teaching basic sanitation, pumping water from nearby Lake Sibayi to reticulate through the hospital and surrounding community, he's helped the community buy tractors for ploughing, set up market and subsistence gardens, built classrooms, a 1000 -seater community hall, a computer centre and sports facilities, facilitated a local market and launched several youth employment projects. He also helped start an AIDS orphanage, and put scores of local matriculants through medical school, celebrating their return for community service with his trademark guitar-playing evenings at his home, which acts as a social centre of succour and support. Ironically, he was suspended in 2016 after members of healthcare unions went on strike over the alleged unfair handling of applications for a handful of general orderly posts. Politicians and union members involved in a local election stirred the pot and Fredlund became the fall guy, as healthcare delivery 
and the weekly hip replacement surgeries he performs went out of the window. Elaborate and clumsy disciplinary proceedings against him petered out and he returned to his job, irritated but showing no rancour. Similar treatment of hospital CEOs at several hospitals in the Eastern Cape has occurred in recent years.

\section{Discovering XDR-TB and setting treatment guidelines}

Yet our doctors continue to rise above such temporary challenges. In true missionary spirit, veteran rural doctors Tony Moll and Francois Eksteen have turned Tugela Ferry's Church of Scotland Hospital into an international beacon of best prevention and treatment practice for extensively drug-resistant tuberculosis (XDR-TB). They were the first to uncover what turned out to be an alarming countrywide XDR-TB prevalence (2005 - 2007).

In the private sector, initiatives like the Smile Campaign do pro bono work (in their case, maxillofacial procedures) country-wide. Numerous 'township' NGOs, like SHAWCO (UCT's Student Health and Welfare Centres Organisation) and Médecins Sans Frontières, continue to deliver quality primary healthcare in under-resourced communities, their volunteer doctors working long hours for little or no remuneration, constantly exposing themselves to occupational hazards such as HIV/TB and violence that can spring up at any time.

These are men and women who epitomise selfless service, commitment and leadership, and they deserve annual honouring for a single day in a country that has yet to give up on its dream of a thriving rainbow nation where the inequities of history are slowly ground away.

\section{Chris Bateman}

Cape Town, South Africa

chrisbat8@gmail.com

1. Medical Brief. SA's shortage of medical doctors - a bleak picture. 19 October 2016. https://www. medicalbrief.co.za/archives/sas-shortage-medical-doctors-bleak-picture/ (accessed 8 October 2018).

S Afr Med J 2018;108(11):891-892. DOI:10.7196/SAMJ.2018.v108111.13694 